\title{
Acerca de la adecuación de la traducción al receptor
}

\author{
GERD WOTJAK
}

0. De la complejidad de los problemas teóricos y prácticos involucrados en esta temática asi como del tiempo limitado se desprende la necesidad de esbozar someramente la mayoria de los aspectos tratados o mencionados dejando su ulterior esclarecimiento para la discusión. Las cuestiones por entablar aquí se encuadran en una problemática general de las interacciones sociales, inseparables de las comunicativas y que tienen que ver con la adecuación del uso que hacen los hablantes/los comunicantes de unos determinados códigos, subcódigos de un mismo diasistema con respecto a su intención comunicativa, al participante en la comunicación, o sea el emisor o los receptores del comunicado o mensaje, así como a la situación comunicativa dada. La traducción como comunicación bilingüe mediada, si bien tiene algunos aspectos específicos, no deja de basarse en los fenómenos que caracterizan la comunicación monolingüe no mediada. Es por eso que dedicaremos mucho espacio a la comunicación monolingüe.

Con esta orientación sobre el habla, el uso o la utilización del lenguaje, sobre la actuación lingüistica, el comportamiento, los actos del habla, los enunciados y la dinámica de la comunicación, se han visto subrayados los usuarios, los comunicantes, el emisor y los receptores en su interacción dialéctica.

0.1 . Se ha podido demostrar que no sólo puede haber cambio de las funciones, los papeles, en el habla, o sea que en diálogos y polílogos el receptor pasa a emisor y viceversa, sino que el receptor, también en el monólogo, participa activamente en la comunicación, ya que el comprender, el descifrar un mensaje, no es menos activo que el decir, el formularlo. Consta, además, que el emisor -al materializar su intención comunicativa - debe anticipar los conocimientos del receptor, su virtual reacción a lo que va a decir, la posición que probablemente adoptará frente al mensaje, cómo lo evaluará, etc. Generalmente, al comunicar tenemos en nuestra mente de emisor una imagen del receptor, o sea disponemos de conocimientos de distinta índole acerca de este mismo, al igual que tenemos una imagen interna de nosotros mismos y que el receptor ya tiene o va adquiriendo determinada «imagen» del emisor. Quisiéramos no decepcionar las esperanzas que abarca el receptor frente a lo que dirá el emisor, a cómo lo dirá y a lo que quiere decirle en la situación comunicativa dada.

0.2. Para garantizar el éxito de la comunicación, el emisor debe adaptar el objeto 
de comunicación y los recursos lingüísticos y extralingüísticos de los que dispone a su intención comunicativa y a los virtuales receptores seleccionando y aplicando estrategias comunicativas complejas para evitar que los receptores no entiendan lo dicho o que rechacen lo que se dice, porque se seleccionó un léxico desconocido, un registro estilistico inadmisible, unas formas de decir que al contrastar con lo usual y admisible provocan - sin que tal fuera la intención del emisor- un rechazo emocional, una protesta por parte del receptor. Resumiendo, comprobamos que para el logro de la comunicación no sólo cuenta lo que se dice, cuándo, en qué circunstancias, a quién, sino también cómo se dice algo en una situación comunicativa dada (la cual en un sentido amplio incluye a los comunicantes).

0.3 . Desde niños, integrados en una determinada comunidad y situación comunicativas y socioculturales, aprendimos a manejar los recursos comunicativos siguiendo ciertas normas y reglamentaciones de interacción social. Aprendimos que tal cosa no se dice o se dice asi, que para decir una cosa se prefiere hacerlo de una forma indirecta por decencia o cortesía, que la reacción a determinadas situaciones interaccionales no siempre implica una participación linguística del recepto del mensaje.

Aprendimos cómo se denominan determinados fenómenos, estados de cosa, sucesos y acciones, almacenamos en nuestra memoria no sólo el liamado fondo lexical común, sino también una determinada cantidad de lexemas que designan aspectos específicos con los cuales tenemos trato diario, por ejemplo, profesional. Nos adentramos una serie de esterotipos de interacción $\mathrm{y}$ compottamiento social $\mathrm{y}$ aprendimos los correspondientes moldes comunicativos (los escenarios, "escriptos» de la inteligencia artificial), asi como los esterotipos comunicativos/nominativos, incluyendo un número más o menos elevado de unidades fraseológicas idiomáticas. Como miembro competente de una comunidad de comunicación sabemos que se dice shay perros», mientras que en alemán se diría "Vorsicht, Bissiger Hund» -lo que equivaldria literalmente a 'cuidado, perro que muerde'. Tenemos en español estereotipos nominativos de «Hombres trabajando», y en alemán, para la misma señal de tráfico, «Bauarbeiten» 'Obras'. Se suele decir en alemán «Von Nässe schützen» y el estereotipo comunicativo-situacional adecuado del francés seria "Craint la pluie" (este ejemplo se debe a Ettinger y data de 1977). Aprendimos, por regla general sin darnos cuenta, que los alemanes utilizamos frecuentemente las dos formas de la voz pasiva, mientras que los hispanohablantes prefieren construcciones de la pasiva refleja que estructuralmente equivalen a la voz activa. Muchas veces sólo la confrontación de dos idiomas, o también de distintos subcódigos al interior de una lengua o de distintos géneros de texto entre si, patentiza la diferencia existente. Así, por ejemplo, se evidencia en la confrontación de textos paralelos del alemán y el español, todos recetas, modos de empleo para medicamentos, etc., que en español suelen aparecer construcciones del tipo «Agitese antes de usar», lo que tendría el equivalente alemán «Vor Gebrauch schütteln».

0.4. Es decir, a lo largo de nuestra vida social y profesional asimilamos no sólo determinados patrones de conducta social y su correspondiente realización comunicativa, sino que aprendemos también preferencias de uso para recursos lingüísticos existentes en el código y que son características para determinados géneros de textos, no más.

0.5. Sabemos que en dependencia de determinadas situaciones comunicativas, en particular del receptor en cuestión y de lo que se quiere decir y lograr, debemos cambiar de estrategia comunicativa, hacer uso de un vocabulario adecuado, distinto 
del que solemos utilizar, más elevado y menos popular, por ejemplo. Debemos recurrir a distintos registros estilístico-funcionales y hasta tenemos que pasar a otro código efectuando un code switching. Cada hablante nativo adquiere un dominio comunicativo matizado, por supuesto, pero generalmente adecuado para satisfacer sus inmediatas necesidades individuales de comunicación. Este dominio, esta competencia comunicativa incluye generalmente el dominio más o menos extendido del léxico de este idioma, disponiendo en su vocabulario activo y pasivo (que dista mucho de igualar el léxico completo y total del español o el alemán, respectivamente) de unidades léxicas cuyos significados denotativo-referenciales y estilistico-connotativos ha podido adentrar en su totalidad o por lo menos parcialmente. Generalmente puede señalar si se trata de un lexema de esfera de uso vulgar, popular, normal o neutralestándar, de estilo elevado o rebuscado, de connotación arcaizante, de una variante diatópica o diastrática en la terminologia de Coseriu (o sea de un lexema que forma parte de un subcódigo sociolectal, por ejemplo, la jerga estudiantil o de los soldados, los criminales, etc.). La competencia comunicativa abarca, además, conocimientos de combinatoria de estas unidades léxicas, lo cual implica el dominio de las reglas (sintácticas) que la rigen, reglas que se adaptan, se adecuan, ellas también, a las distintas situaciones comunicativas (citemos a titulo de ejemplo las construcciones elipticas del habla y de la norma).

0.6. Podemos observar divergencias individuales y sociolectales (Ghasta qué punto también regionales o dialectales?) en cuanto al dominio comunicativo, el cual se traduce por un dominio más extendido del léxico, incluyendo los estereotipos nominativos específicamente adecuados para determinados géneros de texto o estilos funcionales, por una mayor desenvoltura y virtuosidad al manejar el instrumento del código en las más diversas situaciones (partiduras) satisfaciendo a necesidades comunicativas multifacéticas. Mayor maestria comunicativa significa no sólo poseer en su vocabulario idiolectal mayor cantidad de lexemas (pasivamente), sino implica también saber utilizarlos activamente en concordancia con la situación y la intención comunicativas. Implica saber aprovechar los matices estilísticos y sus efectos comunicativos, tener en cuenta el papel comunicativo-situacional del que habla y del que oye o lee, las circunstancias en las cuales se desenvuelve la comunicación, preceptos combinatorios que existan para determinado género de texto, etc. Maestría comunicativa requiere adecuarse, pues, al conocimiento lingüístico del receptor, elegir entre el léxico aquellas variantes diatópicas o diastráticas que - sin obstaculizar la transmisión del comunicado- por el contrario lo hagan más comprensible, más efectivo para el emisor y el receptor.

1. En lo que sigue, principalmente, nos referiremos a las variantes diatópicas, o sea a dobletes regionales coexistentes o no con un lexema sinónimo estándar. Al hablar de la variación en la perspectiva de la traducción menos nos dedicaremos a continuación a la variación diastrática, siendo esta última menos explorada para el español y predominante la diatópica en la bibliografia al respecto. ¿Seria ventajoso, tal vez, el usar las palabras carro, bata, dirección, en lugar de coche, albornoz, señas, como equivalentes de Wagen/Auto, Bademantel, Adresse/Anschrift para hispanohablantes de Hispanoamérica o de España, respectivamente? ¿Podría tolerarse la palabra muy regional guagua en lugar de autobús cuando se dirige a un canario (que también conoce este regionalismo), a un argentino o español, o bien a un chileno para quien guagua significa 'niño/bebé'? Si el emisor y el receptor coinciden en el conocimiento de la variante diatópica, tanto en lo que a su forma como en lo que a su 
significado, o mejor dicho, la totalidad de sus significados se refiere, no hay peligro para la comunicación, la comprensión del mensaje, incluyendo sus aspectos ilocutorios y perlocutorios.

1.1. Siempre se producirá por el uso de la variante diatópica un efecto de localización e identificación del que habla con una determinada comunidad de comunicación y región geográfica y geopolítica. El uso de una variante diatópica puede ocasionar, sin embargo, efectos positivos y negativos. Asi, por ejemplo, el uso de una determinada variante diatópica, o sea de un lexema de cierto subcódigo regional o dialectal, puede señalarle al receptor que el emisor procede de la misma región o comunidad de comunicación o bien que ha permanecido alli, produciéndose así un efecto comunicativo secundario, suplementario de integración, de solidaridad humana y social. Puede causar también una reacción negativa, o sea no siempre se acogerá con simpatía una variante diatópica por parte de los receptores y tales casos de rechazo son particularmente significativos en este contexto. Cambia de valor la fuerza integrante inherente a las variantes diatópicas si éstas se utilizan por personas obviamente ajenas a la comunidad de comunicación al respecto. Una copia imperfecta y hasta la más perfecta posible de la pronunciación diatópica cubana de un regionalismo lexical típico, podrá rechazarse en la boca de un extranjero, al igual que se ve rechazado el esfuerzo de un adulto para acercarse a los jóvenes utilizando su jerga como si fuera un verdadero insider. Resulta difícil pronosticar cuándo se produce tal rechazo, que en ningún caso pone en peligro la comunicación, mientras que el no utilizar variantes diatópicas para receptores cuyo inventario léxico sólo contiene tal variante y que desconocen el doblete o el lexema neutral estándar eventualmente coexistente si se puede correr riesgo de malograr la comunicación. Aconsejamos prudencia y moderación sobre todo en la imitación fonética y entonatoria de la variante diatópica correspondiente, pero también en aquellos casos, donde la variante diatópica se reduce a la variación en una sola acepción de una palabra de amplia difusión suprarregional y hasta estándar y donde el contexto comunicativo y textual no admita la deducción correcta de la acepción desconocida o divergente de la palabra en cuestión (véase más adelante).

1.2. ¿Cómo proceder, sin embargo, si el emisor y el receptor (en tanto que una nación o hablantes de una región) no coinciden en el conocimiento de la variante léxica diatópica al respecto? Podemos excluir aqui divergencias o bien convergencias parciales morfológicas, como en los lexemas «parqueo/aparcamiento, parquear/aparcar». Nos interesarán los casos, donde los receptores no tienen almacenados en su inventario idiolectal, en el léxico del subcódigo situativamente apropiado, los lexemas, como fruta bomba o banana, por ejemplo, o donde no hayan adquirido una acepción especifica de una determinada palabra que con sus otras acepciones si forma parte de su vocabulario activo o pasivo (ejemplo: conducir (España/Canarias)/manejar (en muchos paises de Hispanoamérica); o bravo, que en Chile se utilizaría para un perro o toro, mientras que en Cuba, por ejemplo, muy bien se aplica a los hombres). El uso del regionalismo Rl cuando éste no se puede evitar (para conservar la localización sintomática del hablante transmitida por la variante diatópica) ni sustituir por el regionalismo R2 (este o bien una variante $R 3$ que forme parte del inventario léxico de los virtuales receptores)-- complicará, sin lugar a dudas, la comprensión y puntual y momentáneamente puede hasta obstaculizar en parte la comunicación. Deberíamos evitar, pues, en la medida de lo posible cualquier uso de variantes diatópicas que no formen parte del vocabulario de los receptores y esto con 
más razón si la utilización de tal variante desconocida no se debe a necesidades comunicativas ineludibles del comunicado y el emisor (por ejemplo, la apariencia de variantes diatópicas en el original, el texto de la lengua de partida para la traducción - véase más adelante-), debemos en todo caso determinar de qué receptores se trata y qué léxico forma parte de su compentencia comunicativa y debemos conocer muy bien la extensión/distribución respectivas de las variantes diatópicas, si el doblete en cuestión con mucha probabilidad se utiliza, se prefiere o todavia se entiende si bien no se utiliza por los hablantes de una determinada región. Esta descripción por hacerse todavía en buena parte del nuevo continente no sólo destacaría las variantes nacionales y regionales coexistentes, sino permitiria mejor circunscribir la norma culta supranacional y supraregional (siendo la base para esto la descripción de las normas cultas de los distintos países iberoamericanos --véase el conocido proyecto PILEI). A tal forma supranacional podriamos recurrir en los casos donde el uso de una variante diatópica correria el riesgo de malograr la comunicación.

1.3. Además de los fenómenos apenas esbozados del conocimiento lingüístico, entran en juego en la comunicación también complejos mecanismos de interacción con otros sistemas de conocimientos, entre los cuales predomina el conocimiento llamado enciclopédico, el cual también desempeña un papel importante en el logro de la comunicación monolingüe y eo ipso también para la comunicación bilingüe mediada, o sea la traducción. Tomar en consideración al receptor de la lengua de llegada (Lll) no sólo significa, pues, tener en cuenta que este receptor dispone de otro idioma, de un diasistema y de subsistemas diastráticos y diatópicos virtualmente distintos, de modos y normas distintos de producir y estructurar un determinado género de texto, de preferencias específicas en el uso de los recursos sistémicos de su código materno o extranjero. Significa también que dispone de patrones de conducta moral y social virtualmente distintos (por ejemplo, considerar como falta de cortesía no poder informar a alguien; rechazo al decir -voy a pensarlo...) y que se ha formado en una situación sociocultural y comunicativa algo distinta cuyas divergencias se reflejan no sólo en la ausencia de lexemas o estereotipos nominativos ya disponibles (las «lagunas léxicas» en el caso de la equivalencia cero/nula, los llamados roles), sino también en divergencias en los conocimientos previos enciclopédicos, en «lagunas conceptuales, nocionales» siempre reparables, en divergencias relativas a la valoración emocional, moral e ideológica de determinados aspectos de la realidad sociocultural en cuestión. Adecuar la traducción al receptor, es decir adecuar el texto Lll a los receptores de Lll para reproducir el efecto comunicativo promedio que provocaría el texto de $\mathrm{Lp}$ en los receptores de $\mathrm{Lp}$, implicará procurar compensar el diagnosticado déficit de información previa, de conocimiento previo promedio de los receptores de Lll frente a la realidad sociocultural en la que viven los receptores de $L p$, implicará compensar - en la medida de lo posible- divergencias de valoración probables. Esto se alanzará mediante explicaciones textuales (intra o subtextuales) de aquellos aspectos que se consideren no involucrados en una reproducción de la información léxica contenida en el texto de Lp (sin cortar, por ejemplo, la cantidad de alusiones que se vinculan con textos políticos, dadas las presuposiciones situativocontextuales). Ejemplo: Se tomó otro Matusalén (er trank noch einen Methusalem beliebte Rummarke in Kuba).

1.4. Adecuar la traducción a los virtuales receptores de Lll implica saber quiénes serán estos receptores, lo que significa:

a) Diferenciar en el caso de textos sociopolíticos fundamentalmente en dos 
comunidades de comunicación distintas según que vivan en una sociedad socialista (como Cuba y la RDA) o en un régimen social distinto.

b) Poder establecer con mayor o menor seguridad el probable déficit de información previa relativa al objeto de comunicación tratado en el texto de Lp y a reproducir en el texto de Lll; saber lo que hay que explicitar en el texto de Lll de lo que quedó implícito en el de Lp o lo que hay que reducir, omitir en el texto de Lll en el caso de un superávit de información que les parece muy bien conocida a todos los receptores de Lll y cuya explicitación textual causaria disgusto en los receptores.

c) Determinar el léxico que se utiliza en el texto de $L p$ y por utilizarse de preferencia en el de Lll, teniendo en cuenta las variantes diastráticas y diatópicas utilizadas en el texto de Lp.

2. En cuanto a las variantes diatópicas (y las diastráticas aquí algo descuidadas) y sus implicaciones para la traducción, podemos enfrentar grosso modo, los siguientes casos:

I. El texto de Lp contiene variantes diastráticas que desempeñan determinadas funciones comunicativas, permitiendo la ubicación del emisor en la escala social existente y diferenciar debidamente los usuarios y esferas de comunicación; las unidades léxicas pertenecen a un determinado gènero de texto. Se podrá traducir este texto generalmente sin ulteriores especificaciones en cuanto a sus receptores en la Lll; podría tratarse en tal ocasión de unos destinatarios lo suficientemente competentes como para dominar el estándar vigente, la norma culta incluyendo sus más importantes matices estilistico-funcionales, o sea de un número relativamente muy elevado o bien bastante restringido a una comunidad de comunicación de profesionales. El traductor deberia procurar reproducir el matiz afectivo, emotivo, positivo o peyorativo, inherente al uso de vulgarismos, expresiones populares, arcaizantes, elevadas y manierismos, etc., que contiene el texto de Lp utilizando expresiones del mismo nivel y/o registro estilisticos de la Lll. Se enfrentará a dificultades sólo en los casos donde no se encuentren equivalentes semántico-denotativos y estilísticos. Tendrian que escogerse los estereotipos nominativos usuales de la Lll (otro ejemplo sería dale-los, vorwärts, ataja-haltet den Dieb).

II. El texto de Lp contiene variantes socioculturales o bien peculiaridades socioculturales típicas para la comunidad de comunicación de Lp y desconocidas por los receptores de Lll, o sea el caso señalado de los reales, de la equivalencia cero o nula. Para remediar las divergencias o la ausencia en el conocimiento enciclopédico de los receptores de Lp y Lll hay que explicitar el déficit de información previa, cuyo conocimiento se considera indispensable para garantizar una equivalencia, una casiidentidad del efecto comunicativo promedio entre TLp y TLll.

III. El texto de Lp contiene variantes diatópicas que no sólo permiten ubicar regionalmente el emisor, sino que a menudo conllevan una caracterización social o moral de este mismo (cf. las implicaciones sutiles, pero obvias del que habla sajón, por ejemplo). El traductor (este caso se da preferentemente en textos literarios) debe decidir si va a reproducir el matiz regional y sociocultural del léxico dialectal o regional utilizando recursos diatópicos de Lll que forzosamente ubicarían al receptor en otro ambiente geográfico, por lo cual parece muy arriesgada la reproducción de una variante diatópica del texto de $\mathrm{Lp}$ por otra forzosamente distinta de Lll. Se podria recomendar la reproducción de una variante diatópica por el léxico estándar (neutralización) o variantes diastráticas apropiadas (lo que podría llamarse trascodificación) y la eventual explicación (localización metalingüística, metacomunicativa. 
Ejemplo: habló como los orientales, como la gente de - contestó en su berlinés inconfundible..., etc.).

IV. El texto de Lp no contiene elementos léxicos propiamente diatópicos; se trata de un texto sociopolítico sobre una realidad socioeconómica típica, por ejemplo, de nuestro pais, y debe traducirse al español. ¿Cómo proceder en tal caso si

a) se trata de una traducicón para receptores que viven en otro sistema social distinto y que desconocen, por consiguiente, la realidad descrita en el texto de LP (compárense las reflexiones bajo II);

b) se trata de una traducción para receptores que viven en un sistema social muy semejante (por ejemplo Cuba y la RDA)? ¿El mercado paralelo que denomina una realidad socioeconómica de Cuba parecida a una existente en la RDA debe considerarse el equivalente idóneo traduccional de nuestra $\mathrm{HO}$, la empresa consolidada correspondería a nuestra VVB? ¿Y la Feria de los Forjadores del Futuro se ofrecerá para nuestra Messe der Meister von Morgen (MMM)? Para aclarar si se trata de equivalentes traduccionales, o sea comunicativos idóneos, habrá que comparar la intensión y extensión de los significados asociados a ambos términos y en el caso de una coincidencia total o mayoritaria podrán utilizarse como equivalentes, siempre y cuando se trate de traducciones hechas con vistas a receptores de la RDA o Cuba, respectivamente.

La situación cambia en el caso de que la traducción esté destinada a otros receptores o incluso a receptores no cubanos exclusivamente (véase la publicación Puente y RDA, respectivamente). En tal ocasión debería procederse a una reproducción literal del significado del lexema original renunciando al equivalente cubano ya acuñado, siempre y cuando se considere que su uso transmitiría un matiz local demasiado fuerte (cubanismos o realidad de Cuba y no de la RDA), sin garantizar, a lo mejor, una comprensión cabal, si admitimos que la realidad socioeconómica de Cuba se desconoce entre los receptores hispanohablantes en cuestión.

Resulta más fácil traducir textos para receptores que viven en una situación comunicativa y sociocultural semejante (sobre todo por las razones mencionadas bajo II), pero no es del todo imposible la traducción, incluso de aquellos textos dirigidos exclusivamente a los receptores de $L p$ y que tratan aspectos específicos de. la vida sociocultural de estos mismos (la categoría de los textos no aptos para la traducción en la terminología de Neubert, 1968) y que va destinada a receptores que viven en sistemas sociales distintos.

V. En textos de Lp que enfocan objetos de comunicación de índole general o científico-técnica y que no contienen variantes diatópicas (ni diastráticas las ủltimas) o que las contengan (por ejemplo, frigidaire por refrigerador en Cuba, concreto por hormigón), pero en un léxico no sociocultural ni político-económico, donde pueden o bien deberian al traducirlos utilizarse elementos diatópicos, o sea elementos de uso regional, para garantizar asi -.presuponiendo que se conozca bien a quienes va dirigido el texto traducido- una mejor o más fácil comprensión y quizá como matiz pragmático suplementario el hecho de que da placer sentirse apostrofiado en la variante regional acostumbrada y no sentir ningún distanciamiento por un vocablo cuyo significado se desconoce o que se considera como algo extraño y que "no se diría entre nosotros ni se diría asím. 


\section{BIBLIOGRAFÍA}

S. Ettinger (1977): “Wiederholte Rede' und Bibelsprache», in: Ubersetzung und Sprachpraxis. Beiträge zum Übersetzungsunterricht an der Universität. Augsburg/ Hausdruck, 51-77.

A. Neubert (1968): «Pragmatische Aspekte der Übersetzung», in: Beiheft 2 zu Fremdsprachen, Leipzig.

G. Wotjak (1968): «Zur Übersetzung politischen, philosophischen und administrativen Wortschatzes', in: Beiheft 2 zu Fremdsprachen, Leipzig, 99-107.

G. Wotjak (1985): «Illokution und Perlokution in translatjonslinguistischer Sicht», in: $L A B$. 